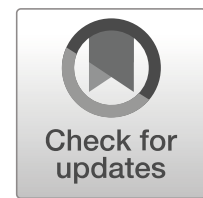

\title{
Platforms, Scales and Networks: Meshing a Local Sustainable Sharing Economy
}

\author{
Ann Light ${ }^{1,2} *$ (D) \& Clodagh Miskelly ${ }^{1}$ \\ *1 University of Sussex, Falmer, BN1 9RH, UK (Email: ann.light@sussex.ac.uk); ${ }^{2}$ Malmo University, \\ Malmo,Sweden (Email: ann.light@sussex.ac.uk)
}

\begin{abstract}
The "sharing economy" has promised more sustainable use of the world's finite resources, exploiting latency and promoting renting rather than ownership through digital networks. But do the digital brokers that use networks at global scale offer the same care for the planet as more traditional forms of sharing? We contrast the sustainability of managing idle capacity with the merits of collective local agency bred by caring-based sharing in a locality. Drawing on two studies of neighbourhood sharing in London and analysis of the meshing of local sharing initiatives, we ask how 'relational assets' form and build up over time in a neighbourhood, and how a platform of platforms might act as local socio-technical infrastructure to sustain alternative economies and different models of trust to those found in the scaling sharing economy. We close by proposing digital networks of support for local solidarity and resourcefulness, showing how CSCW knowledge on coordination and collaboration has a role in achieving these ends.
\end{abstract}

Keywords: Sharing economy, Resource management, Platform, Trust, Values, Mesh, Culture, Local, Place, Scale, Networks, Collective local agency, Sustainability

\section{Introduction}

Sharing economy digital platforms have been hailed as a way to manage finite resources to improve sustainability (e.g. AIRBNB 2014). At the heart of this is care for planet and climate, the protection of which entails developing forms of robustness such as social cohesion, collective action, fairer societies and mindful consumption (e.g. Randers et al. 2018). This requires global action at many levels (IPCC 2018), defined in terms of mitigation and adaptation ${ }^{1}$.

This paper looks at how digital support for sharing practices might be designed to contribute to these goals. Introducing two studies of locally-managed platforms it builds on an analysis of the 'relational assets' generated through layers of collective

\footnotetext{
${ }^{1}$ Mitigation means reducing the causes and/or effects of climate change and adaptation involves adjusting, developing resilience and being resourceful to deal with the impacts. While there is confidence that human adaptation is possible, mitigation is less certain and, nonetheless, also relies on willingness to work together to change behaviours and approaches, i.e. both require social cohesion.
} 
neighbourhood sharing (Light and Miskelly 2015). Relational assets are the social benefits that emerge over time from local sharing initiatives, making further initiatives more likely to succeed. We offer recommendations for measured sociotechnical intervention to develop a platform of platforms, so that these relational assets can contribute best to social sustainability. Relatedly, we adopt the concepts of mesh and scale to describe how platforms orientate to the physical spaces and activities of their users. As sharing is intrinsically social, requiring acts of collaboration and coordination to achieve resource management, we see CSCW as a good home for this discussion and the infrastructuring we propose, beyond the organization and into the neighbourhood.

While much of this paper is an examination of structures of neighbourhood sharing, presenting a cross-section and a longitudinal slice of London life, it is set against the rapid rise of the platforms of the sharing economy. Focusing on finite resources, rather than the movement of infinite intangible goods such as computer files (e.g. Aigrain 2011), we show how networks and platforms can support sharing in multiple ways that feed into better resource management. But we also seek to make the point that some ways of pursuing this are more sustainable than others (see Fig. 1). The findings suggest it is too simple a claim that sharing is good for the environment on the basis that, by making use of idle capacity, sharing uses fewer material resources than other forms of exchange (Curtis and Lehner 2019). This may be true, but the organization of sharing (and its relations with network technology) shows a link between the social aspects in caring-based sharing and environmental benefit, with the social cohesion fostered supporting capacity to mitigate (change damaging behaviour) and adapt (adjust to new conditions) in the face of global challenges (e.g. Randers et al. 2018; Raworth 2017). Our contribution is to reveal how CSCW insights can accelerate (and protect) caring-based sharing. Our orientation speaks to Dillahunt et al.'s (2017) recognition that discussion of topics 'related to the pre-sharing economy' is lacking (p. 11) though we would argue that we discuss sharing beyond the sharing economy (as they and others articulate it), rather than before it, i.e. we focus upon current activity not directly touched by new commercial networked models. We use this alternative approach to reconsider how technology is implemented.

The paper is organised as follows: a review of the opportunities and challenges of sharing; definitions of the sharing economy, scaling and meshing; two studies of neighbourhood sharing (cross-sectional and longitudinal); a discussion of spatial, social and economic characteristics and the types of network that support them; a conclusion offering a critique of current emphasis.

\section{Sharing economies}

Sharing is a collaborative economic strategy, managing resources by borrowing /lending or collectively owning/acting/using. Studies show a range of physical goods and other finite, but less tangible, things get shared by and between people (e.g. Belk 

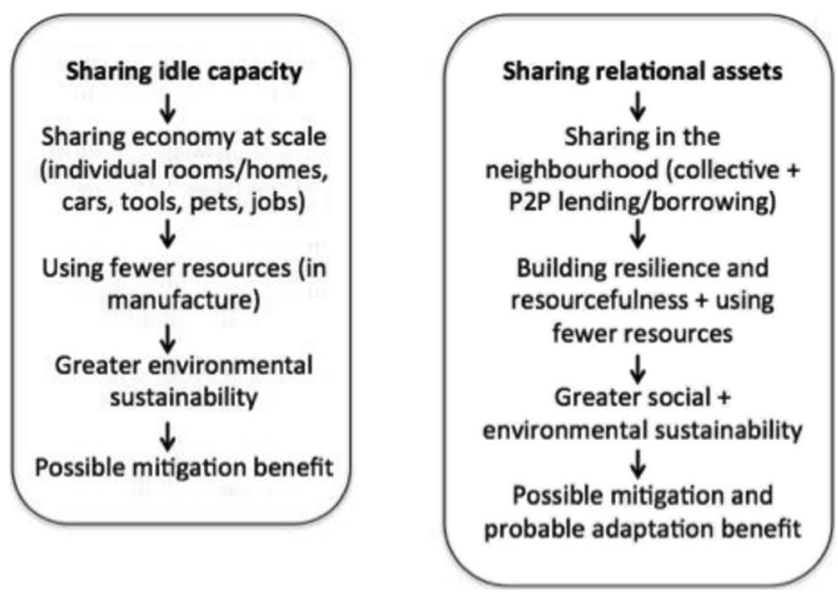

Figure 1. Two understandings of sustainability and their relation to sharing.

2007). By way of introduction to our themes, Table 1 gives one answer from a short online survey on what counts as sharing, capturing a variety of more and less tangible things, lightweight organization and a mix of lending/borrowing and collective ownership, action and use (Light and Miskelly 2014). We note also the respondent's mention of 'neighbourhood' - no scale was specified - and the absence of custom technology.

\subsection{Sharing as a social good}

Sharing, understood as collective ownership (e.g. tools), use (e.g. nanny services) and/or action (e.g. group buying), borrowing and lending, may make resources stretch further, but it is not an austerity measure or linked to one social echelon (White 2009). Eagerness to share comes from a desire to help others, feel needed, and create a sense of belonging. An 'over-riding need for many respondents to feel wanted by others, resonated deeply in both affluent and deprived households' (ibid,

Table 1. One person's responses about sharing activities (Light and Miskelly 2014).

Q1 [What do you share?]: My neighbourhood has a mailing list where we post info of common interest or ask for suggestions/help. We use the list to borrow from each other (e.g. dehumidifier, long ladder, etc.). We also share a shredder for garden waste and we buy (good) food as a group so we pay less. We have considered installing solar panels on the roofs of most houses but it is still too expensive. We also share a "walking bus" to school with children trooped in pairs and only 3 parents to walk to school. And we leave plants or other things on the street for others to pick up.

Q2 [How do you manage your sharing activities?]: The highest technology is a mailing list. Most is done on paper, e.g. leaflets and street chat. 
p. 467). Gauntlett, discussing happiness, concludes that, for activities to be meaningful, it is especially valuable if they 'involve some form of sharing, cooperation or contribution to other people's well-being' (2011, p. 126). Belk points to the benefits of a less material lifestyle (2017b) as part of 'caring-based sharing' (Belk 2017a), helping to create bonds and feelings of commonality.

The importance of sharing goes beyond feel-good qualities. Sharing involves long-standing economic models that are structurally different to selling/buying. Benkler juxtaposes the legal enforcement and crisp interactions of markets with the contextually rich activity of sharing, noting this involves its own, subtler, exchange mechanisms (2004). Sharing seeks bonds and enduring commitment, whereas 'commodity transactions are balanced with no lingering indebtedness and no residual feelings of friendship' (Belk 2007, p. 127). Albinsson and Yasanthi Perera (2012) speak of a sense of community both as driver of participation and the outcome of sharing events. These long-established practices of sharing are emphatically not the selling of spare or idle capacity (unused rooms, cars or goods); they have their own dynamics (Benkler 2004).

In sum, 'caring-based' sharing emphasizes social rewards and operates with a different economic structure from trade. In this paper, we adopt Belk's concept of 'caring-based' to point to sharing that generates 'caring interpersonal ties and a sense of community' (2017a), noting that sharing and social sustainability - the resourcefulness and resilience of community - are tightly linked. Sharing offers a chance to bring resourcefulness to the environmental virtue of using less.

\subsection{Challenges and threats}

But sharing is not a panacea that operates without conflict or discrimination. Individual sharing can exclude those with fewest means (Dillahunt and Malone 2015; Lampinen et al. 2015a; Vyas and Dillahunt 2017). Stigma attaches to it in less affluent contexts (Coote and Goodwin 2010; Offer 2012). And it is complicated to manage commonlyheld goods. Orsi's analysis of infrastructure (2009) shows the increasing coordination required in progressing through degrees of sharing from informal to regional. There may be nervousness about trusting others (e.g. Slee 2015), particularly as structures grow. Collective sharing means giving time to creating structures for organizing and communicating as well as sharing (e.g. Ostrom on the commons, 1990, 1996). Adherence to procedures is decisive for success (Cox et al. 2010).

Meanwhile, Belk suggests that Western societies are headed towards less, rather than more, caring-based sharing (2007). Sennett identifies changes in how Britons and Americans live that undermine an ability to cooperate (2012). If cooperation is a craft, he argues, we are not working hard enough to develop it. Caring-based sharing is being replaced with commercial interaction (Belk 2014; Martin 2016), while the 'sharewashing' of marketing language (Kalamar 2013) makes it harder to detect the shift. 
Makwana (2013) speaks for many in his concern that 'by attaching too much emphasis on self-interest and personal gain in relation to the concept of sharing, the altruistic aspects of sharing could be undermined.' (np). Indeed, a range of research argues that using financial reward to promote concern for greater-than-self issues, such as the environment, reduces individuals' willingness to engage and risks losing societal incentives to make significant change (e.g. Crompton 2010; Warneken and Tomasello 2008; Steed 2013).

Benkler (2004) warns that letting financial mechanisms squeeze out sharing initiatives is mistaken. Yet, Martin et al. (2015) note pressure to commercialize on voluntary/not-for-profit sharing-based organizations, not least because innovation funders assume 'all innovators within the sharing economy would be for-profit organisations seeking to establish a financially sustainable business model' (2015, p. 246). It is possible, but challenging, to commercialize without compromising values (Pansera and Rizzi 2018).

\section{The (Digital) sharing economy}

Unlike sharing as a whole, the sharing economy is digitally mediated. Curtis and Lehner's literature review (2019) finds the 'newness' of the sharing economy comes from using ICT 'to facilitate the efficient mediation or exchange between users and providers' (np). Qualities include access instead of ownership, distributed networks of people and goods, and technologies that build and maintain such networks (Botsman and Rogers 2010). In these new systems, software matches people up and digital networks give potential for global reach.

The sharing economy mediates an increasing number of resource management interactions, offering brokering platforms and a structured process for exchange in a growing peer-to-peer marketplace (Bauwens 2012). The rapid global growth of a few brands in the for-profit sector of the sharing economy makes these players most apparent. These platforms scale by adding users without extending their software core (though advertising and servers may need to grow to win and manage new markets). We use the term scalable here to describe platforms using software over a digital network to offer a service in multiple locations without the need of local installation, but we use scaling to indicate that the platform chooses to exploit this potential for commercial gain or other efficiency benefits.

A scaling approach is common in connecting peers and their goods. Scalability is commercially important; the venture capital that supports many start-ups values the potential of platforms to extend turnover faster than costs. This financing demands an aggressive growth strategy: competing with older business but with fewer staff and storage overheads (Slee 2015). Attaining scale is a fundamental because brokering is best as a monopoly, while both ad revenue and percentage-based fee structures need to scale to be profitable, even as peer-to-peer traders suffer inefficiencies (Coppola 2016; 
Powley 2018). However, potential to scale a service varies. Yu (2018) points to global and local network effects, saying, for instance, that ride-sharing has no global network effects ${ }^{2}$; the network effect only applies locally. Though the software is scalable, drivers - and the cultures in which they work - are bounded by location.

We note that a commercial digital brokering platform perfectly exemplifies Benkler's 'crisp transactions' (2004): binary indicators of identity and financial solvency; precise, market-adjusted charges; instant financial exchanges; software overseeing decisions, all operating at a distance. If people trust the platform, they establish legally-binding obligations across space (Lampinen and Brown 2017; Botsman 2017), reducing uncertainty and fostering rental between strangers.

We also note Botsman's phrase 'access instead of ownership', which Curtis and Lehner's review (2019) associates with sustainability. It is with this transition to access models of use and the exploitation of latency that, irrespective of who owns the resource and how much is charged, using idle capacity becomes equated with sharing. With this shift, people are increasingly 'making money from assets and skills they already own' (BIS 2014). We see, for example, room-renting service AIRBNB gain visibility over room-lending service COUCHSURFACING (Ikkala and Lampinen 2015; Jung et al. 2016; Jung and Lee 2017; Lampinen 2016; Lampinen and Cheshire 2016).

Unlike Curtis and Lehner (2019), Frenken and Schor (2017) assess evidence of sustainability supported by the sharing economy, concluding that well-off homeowners profit most, environmental benefits lie mostly in car/ridesharing, and social effects are complex. Against claims of 'common good', they observe that, as more people participate in platforms for economic reasons, social interaction declines, citing the codification of trust into ratings and technical fixes, such as smart locks for home lets, that mean less face-to-face contact. And it is 'possible that sharing platforms may be harmful to social cohesion' (ibid, p. 7): people used to making profit no longer lend to friends and family. Scaling digital tools do not just benefit from a global marketplace, they increase trade and enable forms of globalization, such as transportation, that fuel climate change (Hakken et al. 2016).

\subsection{A scaling platform}

AIRBNB is the 'epitome of the sharing economy' (Williams 2016), using a digital platform to match and vet hosts and renters, market places for hire and claim a virtuous environmental impact (AIRBNB 2014). Pressure to scale comes from investment funds of $£ 3$ bn (Stone and Zaleski 2017). Here, we identify qualities that characterize it as a would-be monopoly at scale:

\footnotetext{
${ }^{2} \mathrm{Yu}(2018)$ argues that its product does not become more valuable because Uber is building its business across many global markets, though this is not strictly true. Uber is collecting behavioural data across markets as a possible prelude to automating its driving force. These aggregated data have market value.
} 
Crisp: The company brokers properties (and 'experiences') using an automated search process, handling vetting and payment.

Scaling, homogenizing: The platform runs at headquarters far from the trade it brokers, using the Internet to perform functions and collect data on users. It is a global brand, the same wherever hosts are based (though countries have imposed local constraints), dependent on travellers and hosts for any given location, but consistent across contexts. Adding a country, region or city does not change this.

Individualizing, monetizing: It enables financial transactions for individual renters and hosts. As a broker, it takes a cut.

Unscrupulous: It acts to weaken existing social and legal protection to increase reach and profit. It mobilizes users against would-be regulators. It avoids tax in most places it operates and offers hosts a way to minimise what they pay. (Beyond its own market, it is driving up rents as people take properties out of rental to place with the service - it takes no responsibility for this 'externality'.)

This is one extreme of a diverse economy enabled by digital networks (Davies et al. 2017). Luckner et al. (2015) point to other sharing initiatives, which focus on smaller, more local communities and do not involve monetization of exchanges (p63), while Bradley and Pargman (2017) discuss the 'for-benefit collaborative sharing economy'. In the next sections, we consider these other platforms.

\section{Towards meshing}

CSCW has looked at many types of digital brokering platform, such as those enabling crowdfunding (Harburg et al. 2015) and peer-to-peer exchange (e.g. Carroll and Bellotti 2015; Ikkala and Lampinen 2015), and, generally, raised issues of collaboration and trust for "sharing economy" platforms (Lampinen et al. 2015b). Here, we add to this body of work in two ways: exploring the idea of 'a platform of platforms' and looking at how such a thing might come into being.

We describe, above, how local sharing activities build alternative economies that are not 'crisp', but full of enduring negotiations. Looking at resource management at local level and the associated relationships that exist independent of digital networks, Katrini (2018), Light and Miskelly (2015) and Light (forthcoming) draw attention to the potential to create sharing culture, from social networks that grow informally and locally: 'to co-produce, manage, and share resources, time, services, knowledge, information, and support based on solidarity and reciprocity rather than economic profit' (Katrini 2018, np). Cultures can foster a solidarity economy (Miller 2009), where actors 'build economic relations based on cooperation and collaboration, ...on mutuality and reciprocity' (Vlachokyriakos et al. 2018, p. 3). 
This action is highly situated. In thinking about solidarity, space changes from an abstract concept, through which networks scale, to a co-constructed and political space (Massey 2005), through which place is shaped as an intersection of activity, history, geography and politics. Our interest is in social structures that support better resource management, essential in making transitions to sustainable living (e.g. Raworth 2017; Randers et al. 2018). We value the allusion to neighbours and sense of manageable distance carried by the term neighbourhood. We seek to build on our earlier analysis - that there are 'relational assets' generated in particular areas (Light and Miskelly 2015) that support solidarity - by looking at how these assets emerge from sharing practices and offer an ecology of mutually-supportive systems in a place $\left(\right.$ meshing $\left.{ }^{3}\right)$.

When we look at how meshing happens, we join scholars interested in infrastructuring (Karasti and Baker 2004; Karasti 2014), described as 'the work of creating socio-technical resources that intentionally enable adoption and appropriation beyond the initial scope of the design' (Le Dantec et al. 2013). Developing upon Jegou and Manzini (2008), who speak of 'a system of material and immaterial elements (such as technologies, infrastructures, legal framework and modes of governance and policy making)' (p. 179), we, therefore, understand a platform not just as a digital foundation upon which things can be built (e.g. Gawer 2009), but as a configuration of people, values, actions and tools and, thus, socio-technical infrastructure for building upon. Platforms are relational (Star and Ruhleder 1994), operating in a temporally layered system of interdependencies. In our accounts here, we see this in the wealth of activities in one area and how they relate to each other over time.

\section{Neighbourhood sharing}

The next sections describe two studies of sharing practice. They focus on London, a major city and cultural melting pot. London's size means neighbourhoods have added significance and some areas regard themselves as villages. The character of London inflects findings, as one would expect.

One study involves interviews with organizers of collective sharing initiatives in a small area, which we first drew on for a single example (Light and Miskelly 2015; Light and Briggs 2017); the other looks at the evolution of a digital platform intended to impact behaviour nearby. All our findings are now brought together, here, to consider how sharing happens at local level across time. Neither study concerns individualized lending, though there are instances of it. The first addresses shared use of common resources, while the second explores a service that promotes buying and selling, but takes an interesting path.

\footnotetext{
${ }^{3}$ Noting that 'mesh' has become associated with 'the meshwork' (Ingold 2011), and happy for some of the 'entangled lines of life, growth and movement' (p63) signified by this to rub off here.
} 
More details are given below, and a research rationale can be found in Light and Miskelly $(2008,2014)$ and Light and Briggs (2017), which report on the two broader projects from which we drew these cases. To combine our findings, we point to themes that appear across both: sharing, trust, localness, connectedness.

\subsection{Sharing in the neighbourhood}

For our first study, we explored the grassroots sharing practices in a small dense urban area (Brockley, London). We drew from the authors' experience of London to identify a diverse inner city area. Brockley residents include students, private rental, owner-occupied houses and flats, social housing and wealthy households. There are couples, families and lone occupants of all incomes, vocations and ages. As elsewhere in the UK, community organizers and facilitators have set up local facilities for collaboration and exchange. We sourced and engaged with seven people holding responsibility for a local sharing-based initiative in this neighbourhood of about 4000 homes to help understand what sharing meant locally and look at the impact of the initiatives upon each other.

To choose a sample, we imposed a constraint that only initiatives taking place within walking distance of each other be considered: within reach in half-an-hour on foot for able-bodied adults. This distance defined our locale, deemed to be as far as neighbours would walk to participate, borrow or lend. After 3 months' research in the area, there were seven initiatives selected for focus (Table 2). All were chosen as independently run and centring on collaborative activity. It will be noted this was not a study of individuals sharing, but of facilities for collective sharing (Table 2 shows what is shared).

We used extensive local observation ( 3 months of daily activities) and word-of-mouth to source initiatives and interviewees for contextual interview (IxD 2018) (emphasizing production, not use). We conducted at least one detailed interview in situ with a person who could tell the story of the initiative as founder/leader and explain their motivation in getting involved. The interviews were semi-structured and, as part, each participant was asked to define sharing and to explain use of information and communication technology (ICT) and digital networks. We then coded the results for content and discourse analysis (after Potter and Wetherell 1987). We broke narratives into sections on function, set-up, business model, language of sharing and role in the neighbourhood. Both authors looked at the data, made separate interpretations, then compared. The results were then shown back to participants and checked for accuracy and acceptability for publication.

In the next sub-section, we outline the initiatives and give an overview of their business model and use of digital tools. 
Table 2. The interviewees in Brockley.

\begin{tabular}{|c|c|c|}
\hline Initiative & Interviewee & Role of interviewee and service \\
\hline Microlibrary & Sebastian & $\begin{array}{l}\text { Constructed it on a whim so that books can be left and } \\
\text { shared. }\end{array}$ \\
\hline Men Shed & Alys & $\begin{array}{l}\text { Employed to set up three sheds in South London, sharing } \\
\text { tools and working space among older men. }\end{array}$ \\
\hline Patchwork & Olivia & $\begin{array}{l}\text { Entrepreneurial businesswoman launched shared present- } \\
\text { funding digital service/platform. }\end{array}$ \\
\hline Rushey Green Timebank & Philippe & $\begin{array}{l}\text { Long-time manager and match-maker, swapping people's } \\
\text { time. }\end{array}$ \\
\hline Ivy House pub & Tessa & $\begin{array}{l}\text { Shareholder on management board of shared ownership } \\
\text { pub and part of original salvage team. }\end{array}$ \\
\hline $\begin{array}{l}\text { Breakspears Mews } \\
\text { Community Garden }\end{array}$ & Jane & $\begin{array}{l}\text { Led initiative to convert derelict space and now principal } \\
\text { gardener of shared food-growing space. }\end{array}$ \\
\hline Brockley Society & Clare & $\begin{array}{l}\text { Long-term resident chairing society facilitating shared } \\
\text { use of local facilities. }\end{array}$ \\
\hline
\end{tabular}

\subsection{The services}

The microlibrary is on a main road in a former phone box. It was adapted over the course of a week by a local resident. None of the original books remain, as they are regularly taken out, traded in and replaced by residents. Apart from a sign explaining what to do, the microlibrary just stands there, used and maintained by the neighbourhood.

Funding model: one-off, adaptation paid for by local resident who did the work to transform it from a disused public phone box after Brockley Society spent $£ 1$ to buy it.

Digital: FACEBOOK (FB) documentation of phone box transformation and occasional posts from FB page about books.

Men's sheds workspace: "Men's sheds" started in Australia as a forum to address men's wellbeing concerns, providing shared tools and support in carpentry and repair workshops. The sheds offer opportunity to use craft skills to socially isolated older men. Our interviewee was setting up one of the first in Britain, along with a UK Men's Shed Association, funded by the Sainsbury Trusts.

Funding model: grant for set-up; modest subscription or pay-per-visit for users to support running costs.

Digital: negligible. The link on the menssheds.org.uk site goes to a general community page; very low use of digital tools for communication about the shed as (potential) members 'tend not to be reached that way' (Alys, organizer). 
Patchwork (www.patchworkpresent.com) is a digital platform business that supports groups of people buying a single collective present. An item is divided into small bundles to buy, shown in a patchwork image on the site. The owner talks about siting a digital business in this area because of the support around her.

Funding model: The company takes 3\% of money passing through. It aspires to be part of the global sharing economy, though there is also a Patchwork store based in Brockley.

Digital: The business collects gift money from anywhere through the platform and offers tools for representing money as pictures of gifts on the website.

Rushey green timebank runs alongside a medical practice. People give an hour of time to someone and, in turn, can claim an hour from another person in the scheme. Numbers have grown continuously, so there is now a distributed model, with five hubs. The practice that it set up saw it as a remedy for issues not easily treatable, such as motivation and esteem. It has won awards for its work in community health and influenced the growth of other banks.

Funding model: a charity supported by local authority and other grants and given premises by the surgery. Time is banked and swapped (i.e. there is no voucher system).

Digital: a lively basic website shares news and events and offers a "Donate" button. Brokering between time-swappers is face-to-face, though they have been exploring a digital tool.

The Ivy House community-asset pub is the first pub in the UK to be listed as an Asset of Community Value and the first building in Britain to be bought for the community under the provisions of the Localism Act 2011, invoked in haste to avoid redevelopment as apartments.

Funding model: loans and government grants secured the building. The pub is a co-operative, run day-to-day by a professional manager, with 371 local shareholders sitting on its committee.

Digital: the pub used social media to organize its share offer. Its website links to busy FB, Twitter and Instagram accounts, with multiple email addresses to manage its celebrity status ("probably the first Asset of Community Value ever') for press, bookings and advice to other groups.

Breakspears mews community garden was a run-down fly-tipping area full of car repair businesses. Big houses look over it on one side, while, on the other, are council flats. People from both helped in its transition, led by a passionate local woman who still organizes the work. 
Funding model: the local authority cleared the site and Brockley Society support enabled it to start up and run.

Digital: a wordpress blog with information dated 2014 and only 4 followers; an email list alert about opening times.

Brockley society is a conservation society set up to represent the interests of people living in Brockley, monitoring planning issues there and beyond. Its free printed newsletter is delivered three times a year to 4000 houses. It runs a 'Midsummer Fayre' and supports the community garden, an annual 'front garden' rummage sale and tree wardens.

Funding model self-supporting with newsletter ads and an annual local fair.

Digital: website with news, newsletter advertising rates and a 'shop', though no merchandise; FB page ( $\sim 1000$ users); Twitter, since 2013 ( $\sim 3000$ followers).

\subsection{Sharing: Perceptions of community}

Brockley interviewees had no simple definition of sharing, but all accounts had things in common: looking outwards to the community, regarding sharing as a positive quality associated with caring and noting there are challenges involved. There was a strong emphasis on the social value, seen in this example:

'The value of sharing is people connecting. It's a social value. I think it goes beyond "I've got a spare drill, you can use that.". In sharing my drill with you, I'm connecting with you and, if I'm connecting with you, I've got potentially a sense of identity with a community of people or a neighbourhood.' (Philippe, time bank).

The creator of the micolibrary also identified a value to sharing beyond individual exchange:

'When you give a book, technically you're making yourself a bit worse off because you're giving away some of your possessions, but the overall cumulative thing is that everyone becomes enriched by it: lots of people making a very small sacrifice.' (Sebastian, micro library).

There was a sense of where this social value leads:

'It brings people together. It makes people happier. It is nice when you walk out on a street and you recognise people ... when you know them to talk to and you know their names. You feel more part of a community.' (Jane, community garden).

It is apparent that, for these initiators, sharing is about doing with and for others. 
Practices involve sharing quantifiable things, e.g. space, tools, and other finite resources, such as time, skills or labour. But this is, crucially, built on less overt sharing of care, responsibility, vision and values, in some cases also memories and history, and, certainly, trust. The drivers of this behaviour could be summed up as:

- Giving something up to be rewarded in better ways;

- Exchange for things other than cash;

- Fixing something for the benefit of everyone;

- Giving something back;

- Experiencing the sense of having made a contribution;

- Pooling time and expertise, skills and resources;

- Being part of something bigger.

This was not merely a pragmatic sharing of unused stuff, though consideration of wasted resources and the local environment also featured in most accounts.

For the people we spoke to, sharing sits within a set of collaborative practices related to place, connection and belonging (White 2009). This affected their thoughts about scale. Whether because of a physical mooring (such as working in a particular garden) or the logistics of co-ordination (such as sharing tools), no one wanted to extend beyond a neighbourhood reach, except the digital whip-round service (where the ambition is global, discussed in Light and Miskelly 2015). The timebank did extend, but the new hubs were all made self-organizing out of recognition that people do not travel far to swap skills, so their reach has stayed constant.

\subsection{Being connected: Links in the neighbourhood}

Another theme that came up strongly was linking up to magnify support, such as working with the local authority, housing associations and other voluntary groups. Clare of Brockley Society cites many instances of cooperation. The society has shared gazebos with the Friends of Hilly Fields and borrowed a shed from Blackheath Conservatoire. She works closely with Brockley Cross Action Group, looking at planning applications together. The Society is helping the St John's Society re-establish itself. Brockley Market also has links. There is the Brockley Social Club that the Society is working to help revive. There are connections to St Andrew's Church, which runs two clubs for old people. The local housing association has worked with the Society on recent street parties. Voluntary Action Lewisham, which coordinates volunteering, sends out Society notices with their newsletter, as does the Pensioners Forum in Lewisham. This list is partial, but given in some detail to show the local weave. 


\subsection{Trust}

A last theme raised by multiple informants was how trust develops over time and how to scale that up. We heard how trust grows in a neighbourhood as people engage together in small-scale collaborations and communal ownerships, which then lead to more ambitious projects as a group. Strangers are welcomed into creative association with others and so cease to be strangers. Leaders emerge and become known and trusted. Informal systems develop that suit those participating - and part of growing this trust in each other is evolving these systems together. People feel that they are contributing, area-wide, to the evolution of trust and systems of collaboration. Even the microlibrary, which requires no particular up-keep, is part of a landscape of initiatives that foster a culture of sharing and has become a symbol for it.

\subsection{Doing things digitally}

We saw a care-based economy operating in their choice of digital technology. Most initiatives used simple off-the-shelf network tools (email, WHATSAPP). But using digital technology had downsides, such as the different use patterns between service organizers and users. The Men's Sheds organizer is confident with TWITTER and 3D printing, but her target users may not have a smart phone or computer and do not use social media, making it laborious to reach them. With the community garden, it is the other way round; the organizer does not like email. There were comments about how easy it is to evade awkward tasks when contacted through a screen. In some cases, digital had been considered and rejected: after discussion, Brockley Society's newsletter remains printed and hand-delivered.

\section{Makerhood, local platform}

Our other study comes from a longitudinal project on platforms for social action. It is picked to speak to choices of scale and neighbourhood impact, drawn from long-term observation of several UK platforms concerned with social innovation, sustainability and societal transformation (see Light and Briggs 2017). Light has been tracking sites with these aspirations since 2007 (Light and Miskelly 2008). More than 10 platforms ${ }^{4}$ have been studied over $10+$ years, with ventures coming, going and evolving. Longitudinal engagement with social innovation initiatives is arbitrary; it is impossible to determine which will endure and possibly achieve their goals. Instead of attempting to sample systematically, a main criterion was access to key decision-makers for each case. Privileged access to initiators' thinking, before, during and after launch, came through personal relationships and intermediary introductions over years of participating in business, social and activist networks.

\footnotetext{
${ }^{4}$ Not included here for reasons of confidentiality, since they are not integral to this paper, though Light and Briggs (2017) gives detail of four others.
} 
Choosing on this basis has had the advantage of allowing the authors to gather detailed and early information on motivations for design decisions, which has informed other work (e.g. Light and Briggs 2017).

The account below involved interviewing key people and tracking decisions and changes as the enterprise evolved. Progress was sampled every few months and founders/other key stakeholders were asked to explain their actions and decisions. Within interviews, attention was paid to claims made for the platform and how interviewees spoke about their goals and we treat them as insight into the decisionmaking process. All interviews were recorded, transcribed and analyzed using content analysis and discourse analysis to trace patterns (e.g. Potter and Wetherell 1987).

The case study was chosen, from others, to provide an illustrative account of design choices in the context of producing a platform for use in a particular locale. It is not given as representative; rather it is informative in looking at certain trends. It is based on several interviews with the two founders, Kristina Glushkova and Karen Martin, as well as observation over 8 years, which included being part of the same research project during 2013. ${ }^{5}$ Quoted material comes from a key hour-long interview with Glushkova in 2011, shortly after launching, unless otherwise stated.

\subsection{Makerhood}

The MAKERHOOD platform was launched in 2010 to connect local craft makers with purchasers. MAKERHOOD is a social enterprise led by volunteers and overseen by a steering group, showcasing the work of local makers in Brixton, a small part of South London, to encourage a buy-local ethos. It was created in answer to the founders' failure to find locally-made goods. At outset, it was an ecommerce brokering platform, but that model gave way during its first years as it became obvious that the platform's value was not to manage money, but to connect and support makers, reflecting the founders' (environmental and social) sustainability goals emphasizing quality of life and reduced consumption. The platform costs less than $£ 3000$ a year to run, including maintenance, insurance, accounting and legal charges. This is largely covered by makers' subscriptions (taking over from the original $4 \%$ levy on sales through the site).

To set it up, the founders looked at what was known about the meaning of buying and owning, learning that people with less money spend on items that are particularly meaningful to them. This chimed with the founders' outlook: 'For me, consumer culture is empty. Part of being a community with different skills is that we make things for each other.' Buying local would reduce footprint; buying specially crafted pieces could reduce overall purchasing.

\footnotetext{
${ }^{5}$ Create, Connect and Sustain (AH/K006592/1). Light was a co-investigator, introducing MAKERHOOD.
} 
Decisions about technology, values and their business approach emerged in discussion with others, including Transition Towns, the local council and people joining as volunteers, such as a designer and developer. 'It was not defining something in isolation from the community, but defining something with them. And it was not starting from what technology can do, but with what we need. Technology was the last bit.' This developed into a devolved structure that allows individuals with responsibility for a feature to shape that component and has stayed responsive to local interests and needs.

'We make changes every day as we learn. We are so local; people know who we are. I live here and I blog about making jam from my allotment in Herne Hill. Trustwise, you'd have to work really hard to make something like that up.'

Issues of trust came up repeatedly in shaping the platform. PAYPAL was used for transactions while there was an ecommerce function, introducing third-party credibility. There were also decisions on how to handle goods. The platform seeks to encourage people to get to know the person who made their object. Storytelling about the producers is a prominent feature of site content. The idea of meeting is embedded; you can send goods, but ideally the maker and purchaser meet for hand-over. To further this and protect makers' privacy, guidance on delivery spots, using streets known to be safe and pleasant, is part of MAKERHOOD's code.

But the MAKERHOOD model shifted from one-to-one meetings between makers and their customers to assembling people with an interest in craft and business. Bringing makers face-to-face to make craft and share concerns became as important as online marketing. Gradually this devolved too and club events were run by local makers instead of the core team. This stayed true as the MAKERHOOD vision spread over the years, with other nearby makers' groups opening in 2012-13 and pilot MAKERHOODs in neighbouring inner London boroughs.

Glushkova said, already in 2011:

'We could scale it and make it much bigger, but we didn't want to do that. It's not an internet project; it's a project about connecting people locally, helping people find things by local makers and helping local makers find each other. The technology can be transferred quite easily, so we are very up for sharing it. [But] I feel quite strongly that we shouldn't be running local Makerhoods; they should be run locally. It's part of an area having it's own identity or finding it in the process of doing this.'

In late 2018, the founders announced that they were withdrawing from MAKERHOOD as directors (Glushkova, interview, 2018). It was never a platform that made its founders money and they have successful careers that compete with maintaining it. They feel they have achieved everything they set out to. Typically, everyone involved has been invited to consider its next incarnation. 


\subsection{Analysing the trajectory}

The MAKERHOOD study describes a platform with a primary ambition to minimize resource use, which it shares with other sharing economy services (Stokes et al. 2014; Curtis and Lehner 2019). The platform primarily supports making, selling and networking, not bringing people together to share goods, however its orientation has promoted a sharing culture. It is of interest because:

1) it is a digital platform aiming to engage people only in a very small area; its ambitions stayed local, with a strong sense that scaling would not suit the project or benefit the neighbourhoods it might scale to;

2) it made a shift from a typical ecommerce brokering function, connecting trading individuals, to a collective approach based in makers meeting and taking increasing responsibility for organization of meetings;

3) the devolved style of management increasingly led to sharing of opportunities, skills, materials and eventually ownership of the platform, to the point where new organizers are taking over from the founders;

4) MAKERHOOD activities have supported new business to take off and contributed, among other organizations, to changes in the area.

Underpinning this is a different economic approach from that seen in the globally-ambitious scaling brokers. MAKERHOOD was a brokering site intended to be self-sustaining, but Glushkova points to a non-profit strategy to achieve this, building on the interests of the people using it and generating the funding to keep it running as a members organization. She describes a collaborative development process in working out what the platform should do, making room for many people to shape policy. In staying volunteer-led, maintenance has been cheap. When much of the process stopped being digitally-mediated, it removed the need for competitive digital competencies. This model of organizational sustainability exists in a local care economy, not the scale-or-die financial system of marketplace platforms such as ETSY, which also promotes craft makers. No one is interested in it being homogenized, individualized, unscrupulous or crisp.

The lack of interest in scaling is bound to this. The financial model does not require scaling, but, more significantly, neither the relationships on which is it based, nor the way that it understood its boundaries of relevance (what is 'local') are scalable. As Glushkova states, they wanted a people-led, local project and were happy to offer the tools to others to create their own local platform.

\subsection{Sharing: Open organization}

MAKERHOOD does not, on the surface, involve sharing. It is a market for objects made with care and a network of small Brixton businesses. However, the structure its founders built to execute these exchanges involves collaborative development, 
maintenance and use (see Table 3 for an analysis of how it sits relative to other platforms) and has changed over time as it learnt, involved new people and responded to changes around it. It has become a hub for smaller initiatives, able to mediate between top-down development in the area and small businesses. The P2P Foundation describes generative ownership (n.d.) as defined by a 'living purpose', 'rooted membership' and 'ethical networks', which seems relevant here, where so many people are able to take partial ownership and adapt it to local concerns. The sharing that MAKERHOOD has devised resembles that in a couple of the Brockley examples, where a local initiative acts as a collective asset, as well as offering a service (community garden; conservation society; pub).

\subsection{Trust}

Trust is a key sharing economy issue (Botsman 2017), because, as Slee (2015) puts it, these platforms bring together 'strangers trusting strangers'. Hawlitschek et al. (2016) describe three foci for trust: peer, platform and product. MAKERHOOD has been principally concerned with peers, allowing this aspect to lead trust in the other respects. Although it used PAYPAL for credibility at outset, as other peer-topeer selling platforms, it then abandoned the vetting element, not because people knew each other by this point, but because local strangers were meeting without the desire for vetting. In other words, its location-specific nature made it a culturally different class of platform.

Glushkova cites measures taken to make the service safe and easy, reflecting a concern for people's wellbeing more related to the ethics of being intermediary than trust as understood in the scaling sharing economy. She does not talk of strangers coming to trust each other through machine vetting (as Botsman 2017); her position is that trust is built between people through repeated encounter and mutual interest, which turns out, at these close quarters, to make the financial component of MAKERHOOD's digital platform unnecessary. Through all her interviews, her concern is for the people engaging with others and responding to their handiwork, not the production of satisfactory items and smooth transactions.

MAKERHOOD addresses privacy and safety by proposing sensible hand-over spots. This is not electing a category of meeting place (such as supermarket or post

Table 3. Different economic relations behind/through platforms in the sharing economy.

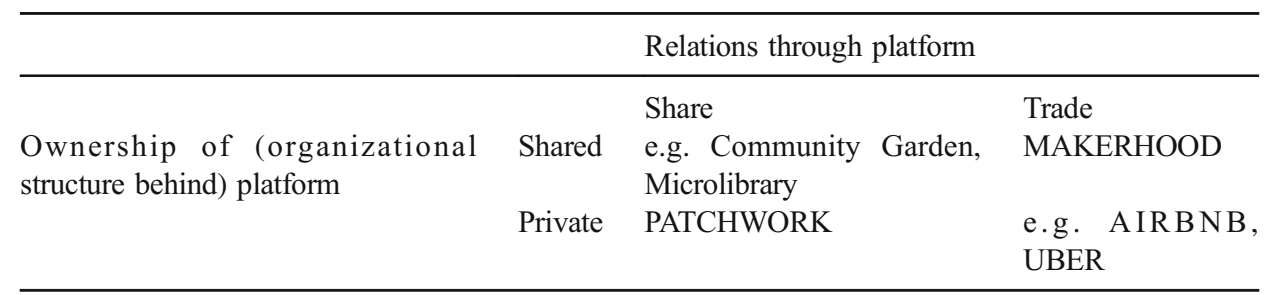


office) as a scaling service might, but naming a particularly safe spot on a particular street, because everyone knows the same streets, including the platform founders. These gestures give people confidence in the founders in the same way that it develops with everyone else. Trust is situated in the places and social relations of MAKERHOOD. The makers in the maker clubs happily lend each other resources; they live near enough to each other to feel connected and to reclaim items between sessions if needed. They see each other on the street. Mutual trust comes from getting to know each other through MAKERHOOD events, for which they gradually take more responsibility.

\subsection{Being connected: Localness}

In building trust and supporting sharing, we see the impact of being local on/as MAKERHOOD's strategy of engagement. This relationship-building could not have happened through a platform that operated remotely; it needed local appropriation of the platform design. It could not have evolved with - and in response to - the growing community or enacted ideas from local makers, attuning to Brixton's characteristics. It could not have involved so many volunteers, each contributing their own judgment. MAKERHOOD's team has made crafting more valuable in the locality, not just by providing a platform to promote it, but through building an accessible organization that crafters can share and expand. It has achieved this, in part, by starting and staying local in ambition, reach and understanding of relations. This is not wholly a result of being non-profit; a sensitive commercial undertaking could also adapt to local circumstances (see Yu 2018, for instances), but then it would also lose the global network effects. There is a tension between appropriability/access to management and scalability.

MAKERHOOD's non-profit ethos is, however, significant; it enabled many people to take a stake in its organization and become part of a shared initiative to promote local trade and 'buying local'. Everyone, including founders, was in it together. An overtly commercial organization is likely to have struggled to inspire so much voluntary engagement; it is hard (though not impossible) to stay true to such social motivation in turning for-profit (Pansera and Rizzi 2018).

We also note they are managing tangible goods. Software development can run as a self-organizing community across distributed space, but a confluence of crafting and 'buying local' point to other organizational ambitions and outcomes.

\section{Discussion}

The studies above show some of the nuances of neighbourhood sharing. It matters where an initiative is based and how it coordinates with neighbouring concerns, how trust is established and fostered, how sharing is understood. It matters what ethos is 
cultivated: individualized or collective; generous or monetized. This affects the development of relational assets for a neighbourhood. Economic factors are significant for relationship-building in an area, and vice versa, and both are linked to spatial dynamics.

In other words, we are comparing scaling and meshing not because they are two ends of a single spectrum, such as for-profit ${ }^{6}$ vs non-profit, or global vs neighbourhood, but because the tight relation between financing, values and reach manifests in patterns of digital network deployment. The use of scaling in the sharing economy is well documented (e.g. Choudary 2015; Moazed and Johnson 2016; Reillier and Reillier 2017). The idea of meshing provides a necessary contrast: necessary not merely to think creatively about network configuration, but because it carries a different environmental heft (see Fig. 1). If we return to the difference between mitigation strategies (such as using fewer resources) and add adaptation strategies (such as building resourcefulness and social cohesion, which relate, too, to willingness to mitigate), we see there is more at stake than levels of resource use.

There are grey areas, of course. Yu (2018, np) reports that Uber is giving way to local services in some areas, identifying 'an alternative strategy for platform growth, one where it's less about geographic spread than about the depth of a chosen market'. We are seeing the rise of platform cooperatism, which brings users into the management of their platform (Scholz 2014; McCann 2018). These trends involve the adoption of 'crisp' software to match-make, vet and manage trust, handle payment, aggregate data and alter algorithms to meet changing needs, but not homogenously, at scale, and not necessarily out of the decision-making hands of those whose lives are impacted.

But this is to discuss platforms at an organizational level. Now we turn to meshing at neighbourhood level and what a platform of platforms might mean.

\subsection{A platform of platforms}

In areas thick with local initiative, there is a discernible mesh that shared infrastructures of sharing can create (Light and Miskelly 2015): a platform of platforms. In previous work, we suggested that 'cultures that emphasize shared resources - and shared making and supporting of shared resources - will be qualitatively different from those where the infrastructure is beyond reach of participants' (ibid). With this latest study, we show how this change of quality happens, bottom-up and unscheduled, over time. It can manifest in a change of software use, as MAKERHOOD's story shows. Trust, we were told by many interviewees (and saw in the longitudinal study), takes time to grow and this, in turn, enables sharing relationships to flourish. Greater trust, at individual, organizational and neighbourhood levels, allows for

\footnotetext{
${ }^{6}$ Most of MAKERHOOD's craft clients are selling to help make a living.
} 
bigger sharing projects and more initiative-taking. This mood encourages further enterprise. These social and technical infrastructural elements progressing together create the extra relational assets, a new platform, meshed from other platforms, upon which further initiative can build. There is both a temporal and spatial aspect.

No individual project sets out to be this mesh or make this additional platform. Many are aware they are part of something that adds up to more than the sum of the parts (for instance, the owner is glad that she situated PATCHWORK in this rich soup, even though she wants it to scale). Yet, this 'situated-together-ness' is relatively undetectable in real time by the actors in the locale that constitute it. It is hard to notice until it gains critical mass. We see it most in Brockley Society's account of sharing across projects and MAKERHOOD's account of how the platform grows.

Table 4 plots access to shared resources in Brixton related to MAKERHOOD's interventions. This is not Orsi's degrees of sharing, which refer to the scale of a single undertaking and associated organizational requirements (2009); these scale together. Instead, this table shows tiers of sharing in a single area. This area does not scale much beyond what is navigable by foot.

Areas are not discrete; they bleed into each other, determined by where people and enterprises are situated. Relative location impacts on sharing because of the materiality of the goods as well as local relations. There is a need for proximity and every sharing arrangement will have its 'own circumference of tolerance, in other words, how far people [think] reasonable to pair up for resource exchange or management' (Light forthcoming). This is true for all tangible sharing, whether through local or scaling platforms.

Distinct from proximity, place is significant too. This is not the abstract space through which networks scale; it is a co-constructed and political space through which place is shaped by intersections of activity, history, geography and politics. The significance of the co-constructed space and how it holds the 'stories-so-far' (Massey 2005 p. 9) helps constitute the platform of platforms. Could these stories be furthered if people were given a technical function to vet, broker and transact? MAKERHOOD decided not.

Table 4. Different layers of shared benefit within neighbourhoods.

\begin{tabular}{|c|c|c|}
\hline Tier & What is in common & Example \\
\hline Neighbourhood & $\begin{array}{l}\text { Shared mesh of mutually-supportive organizations: } \\
\text { relational assets as 'platform of platforms', sharing } \\
\text { culture }\end{array}$ & Parts of central Brixton \\
\hline Organization & Shared or co-managed co-ordination of resources & $\begin{array}{l}\text { Makerspace management } \\
\text { structure }\end{array}$ \\
\hline Individual & Shared or lent resources & $\begin{array}{l}\text { Maker club members } \\
\text { sharing their tools }\end{array}$ \\
\hline
\end{tabular}


In sum, in the studies above, initiators' local knowledge of what matters in a place, their openness to engagement with other people around them and their interaction with other local initiatives are part of how the platforms contribute. Repeated encounters promote types of neighbourhood relations (linked to gentrification, e.g. Okada 2014, writing about the Brixton experience, and/or solidarity, Weber 2011). This embedded place-shaping is in contrast to the contribution of scaling platforms ${ }^{7}$, for instance, Airbnb and Uber 'have been described as Death Stars that extract vast amounts of value from local communities only to transfer that wealth elsewhere, sometimes into tax havens' (Shareable 2018 p. 206).

\subsection{Configuring the mesh}

Can the design of a platform of platforms be enhanced and accelerated? We believe so. Vlachokyriakos et al. (2018), suggest that participation in designing technology for social innovators should result in technical innovation 'that mirrors the characteristics and values of the already designed social innovation, [...with] the capacity to extend socially constructed innovations into wider society and as a result contribute to their scaling-out.' (p. 10). Their comments build on a body of work on infrastructuring (such as Hillgren et al. 2011; Karasti 2014; Karasti and Baker 2004; Korn and Voida 2015; Le Dantec et al. 2013; Pipek and Wulf 2009; Seravalli 2018; Star 1999; Star and Ruhleder 1994), which does not publish systematic recommendations for a design, but instead alerts us to socio-technical characteristics to consider.

We apply this beyond individual organizations. An open, responsive approach to configuration is needed to scaffold neighbourhood strengths and the resource management practices in a particular locale. Across our accounts, we identify several leadership, management and coordination tasks that could benefit from being considered as area-wide activity:

- Understanding and harnessing the potential of technology;

- Managing sharing practices and sharing out work/gain;

- Planning for trust to deepen and spread;

- Making participation with relative strangers meaningful;

- Connecting to other agencies and services;

- Proliferating ideas and learning from others;

- Evolving management to include new actors and their contributions.

In other words, if we define meshing in relation to people, values, actions, tools and place, we see it is a sociotechnical infrastructure of partly-digital networks built by actions of collaboration, sharing and using each other's

\footnotetext{
${ }^{7}$ Large-scale sharing economy platforms such as UBER and AIRBNB also impact on places in ways that reflect existing social formations. UBER has been taking people out of public transport in London (Powley 2018), while AIRBNB has been affecting the lack of affordable housing in already attractive destinations.
} 
resources, with values that include nurturing trust between people and putting fellow-feeling at the heart of the neighbourhood (and rejecting homogenizing, individualized, monetizing, unscrupulous approaches), established by thinking about scale and leadership and what is appropriate to ask of people in terms of distance, work and commitment (e.g. timebank, Brockley Society and MAKERHOOD policies). To mesh is to build mutual commitment within a neighbourhood by layering local sharing initiatives and developing and maintaining local collective agency through their aggregation.

Are there instances of altruistic sharing that involve scaling services across different locales? Of course - and these instances support social sustainability. But appropriation is key to meshing. Taking the work of sharing out of local hands, be it by remote management or over-zealous software intervention, is to weaken the 'shared infrastructures of sharing', even if sharing manifests in individual ways. ${ }^{8}$ Being able to influence the processes involved in managing the infrastructure is a key part of developing this social sustainability.

For Fisher, the 'sociopolitical constellation of our current network society is the result not only of economic and technological transformations but also of ideological transformations' (2010 p. 2). In other words, the dominant discourses ignore the mechanics of sharing and play up the value of the most individualized, monetized and scaled approaches at their peril. We get the world for which we design and advocate.

As a counterweight, we focus on assembling tools to support our insights that:

- sharing, like other aspects of caring-based, alternative and solidarity economies, has to be achieved and maintained;

- this work happens in particular localities, that affect how and why it happens;

- resource management involves using resources well and collaborating to make this happen: both have value in facing resource challenges (and the political instability these create).

So, we finish by looking at how we might deploy network technology to support caring-based actions and social sustainability, enhancing rather than removing local collective agency.

\section{Tools for meshing}

Meshing is not a matter of exploiting digital network effects by designing a one-sizefits-all tool; it is creating the conditions for socio-technical infrastructures of sharing. We need to ask what makes tools work in aggregate, over time, for each context, activity and combination of actors. We can start with the higher-order question: what

\footnotetext{
${ }^{8}$ We note DiSalvo and Jenkins (2017) make a similar point in looking at community foraging - they design to avoid taking the valuable work of community building out of the task. See below.
} 
makes sharing work? Digital networks may be helpful, irrelevant or hindering. They are costly and, in a caring-based economy where there may be little money, this points to finding affordable and reconfigurable approaches.

\subsection{Six examples}

In this sub-section, we suggest some existing and future tools that may be used together in creating mesh to become more than the sum of their parts. All the suggestions are made to enhance current practices rather than replace them. When there is no financial pressure to scale, we can employ digital networks if (and only if) they are of service to support leadership, management, engagement and coordination tasks. A key point is that, for meshing, network tools work best in (place-specific and evolving) combinations, as we saw in the Brockley example. These uses of technology produce additional effects when combined: not scaling broadly, but amplifying locally. So we are drawing attention to a tendency rather then offering a blueprint.

\subsubsection{Understanding and harnessing the potential of technology}

Supporting an evolving combination of network tools takes skill and motivation, which, our examples show, varies between people and initiatives. To strengthen the mesh while considering the changing needs of the neighbourhood and the emerging possibilities in network tools - as the Internet of Things (IoT), sensors (and data collection itself) become useful at local level - could mean including a technology space in the mesh of collective projects. Then the reflexive challenge built into 'understanding and harnessing the potential of technology' can become a dynamic process in the spirit of local exchange.

Toombs (2015) shows how makerspaces thrive on feelings of belonging as well as skill sharing. Hui and Gerber (2017) discuss how, looking beyond purely technical skills, spaces can promote entrepreneurship by leveraging community-based values of social support, exploration and empowerment. These studies suggest the potential for incorporating an initiative with similar values. While the carbon footprint of some makerspaces reflects the resource-hungry nature of digital tools in general, such spaces can also bring education in different types of sustainability (Smith and Light 2017), which is not normally a feature of technical support.

However, as remarked, this is not to employ technology to replace community labour. DiSalvo and Jenkins (2017) describe a sensor system for community fruit gatherers to detect when fruit is ripe. They discuss whether providing this sensor takes value out of collaborative voluntary activity, because: 'appreciating the significant work required to sustain diverse community economies is crucial to designing for community economies' (2017). We share the concern here. It is counterproductive to eliminate socialization work, during which collaborative skills may be learnt. Instead, it is possible to support engagement in low-key and/or pleasing ways. 


\subsubsection{Managing sharing practices and sharing out work/gain}

Digital tools can distract people's attention from the shared environment, or be situated, or even attached, to material elements. Our studies suggest group emails, texts and social media serve coordination well enough, so what else might help?

The growing body of community IoT designs (Fischer et al. 2016) could allow groups to source, learn about, share out and/or borrow things. At the LIBRARY OF THINGS (www.libraryofthings.co.uk), each rentable object has an ID mapping to a central database. There could be decentralized facilities for data about who has what, for how long, etc., adding functionality to items without adding extra tools. Robertson and Wagner suggest that CSCW could support IoT in 'negotiating the boundaries between (networks of) objects and people, making them transparent, understandable and adaptable' $(2015$, p. 9). A system that makes things for sharing more visible and leads step-by-step through how to use them could be valuable. Something as simple as a remote lock to sit on community gardeners' phones might work for some gardens - or be a step too far for others.

Major sharing economy players are trading in data as well as brokering. They use information about services to achieve greater automation or more effective selling. Communities could benefit too from data over time to assess the impact of their activities. Sensors are good at collecting metrics (how much time, weight, power, etc.) for allocating fairly (assuming no in-built discrimination) and even monitoring. This might make allocation of goods, times and produce easier, but could become mechanistic. DiSalvo and Jenkins (2017) use their sensor to report that fruit is ripe, not to share it out. Another approach would be to use the data to consider future needs and configuration of services.

\subsubsection{Planning for trust to deepen and spread}

Trusting peers has a temporal quality, growing with increasing familiarity and success in small engagements, building towards mutual interdependence and larger projects. Confidence provided by insurance through a brokering platform ('trusting the broker') is different from trust in your own judgment of others, but the latter can be cultivated. We see MAKERHOOD understand the dynamics of trust better before divesting itself of digital tools used to promote trusted brokering (digital vetting of buyers and third-party finance partners with credibility).

Tools that scaffold trust can become redundant as relationships grow and more people become involved in helping with local initiatives. Instead of removing the onerous task of growing trust, neighbourhoods could invest in visibility over time for judging others' actions and building confidence. Social networks, where local groups post and discuss, are a resource for building off-line friendships (Barkhuus and Tashiro 2010; O'Hara et al. 2014) and, by giving access to each other in less demanding circumstances, allow trust to develop. This encourages people to get involved in running initiatives and inspires existing managers to involve others. 


\subsubsection{Making participation with relative strangers meaningful}

Brockley Society concerns itself with place and heritage, sponsoring projects in the area and hoping to engage residents in collective activities, such as the annual 'front garden rummage' and meals for older residents. The chair rejects putting the newsletter online. Yet, networked hardware can build the sense of belonging that Brockley Society hopes to instill (and that underpins people's interest in collaborating, White 2009). Examples of networked tools that work this way are Heitlinger et al.'s (2014) IoT watering can, which recounts tales, recipes and growing advice for herbs at a communal farm; her connected seed library (Heitlinger et al. 2018) with stories of growers and plants; and TOTEM (fields.eca.ac.uk/totem), a town storytelling sculpture. These digital repositories are not about efficiency; the novelty and wit of the designs can help lead connection in a profounder way.

\subsubsection{Connecting to other agencies and services}

Multi-agency digital platforms are not yet common, though starting to sit beside other forms of local, collective inter-agency and community problem-solving. An early non-profit example is Adur \& Worthing Councils' 'low code' system that allows community practitioners to link with medical practices and the council to work collectively to reduce stress on health services (Adur and Worthing 2017). The platforms are being used to join up and provide a communication mechanism between community organisations with common interests, many with a history of working alone.

\subsubsection{Proliferating ideas and learning from others}

The microlibrary used FACEBOOK to document its progress from phone box to book repository. The idea has been copied many times. Sharing examples helps concepts scale and adapt for other situations, rather than scaling users for a global service (what Biørn-Hansen and Håkansson 2018, call spreading, rather than growing). Examples of sites providing a platform for ideas about sharing to travel include INSTRUCTABLES (www.instructables.com), where users pool how-to information, FIXPERTS (http://fixing.education/fixperts), posting one-off solutions to a challenge, and SHAREABLE (www.shareable.net), a news site for stories of commons-based, collective and not-for-profit sharing. These sites can help ideas jump between contexts and proliferate (Botero et al. 2016; Messeter et al. 2016), spurring initiatives by supplying blueprints and helping others to reproduce them.

\subsection{The mesh}

Our suggestion for adding technology to sharing initiatives is only indicative of ways that networks can be deployed to be supportive of local context, evolving cultures and collective agency. The tools are ad-hoc and responsive, like the relations being formed. They speak to a valuing of sociality, both for its own sake and for the practical purpose of moving societies towards conditions for greater sustainability 
(e.g. Nardi 2019). They build to support meshing, helping to create, over time, neighbourhoods in which growing interdependence is possible. It is in this sense that the mesh is a socio-technical platform of platforms: a support for heterogeneous economic action and social exchange mechanisms; a relational asset. At its best it is inclusive, involving a broad range of people. Built on these relationships, it cannot grow without further collaborative organizational effort, but it can be recognized and encouraged. Initiatives run more easily here. This can be fostered.

\subsection{Amplification and spread}

A remaining question, then, is whether this type of (vulnerable, but necessary) sociotechnical infrastructuring can proliferate globally over time as well as deepening in one place: what Biørn-Hansen and Håkansson (2018) call 'spreading' in an analysis of the transfer of sustainability-oriented organizations. The scaling sharing economy is characterized by rapid growth across space using scalable technologies. Is there a subtler equivalent and how might technology support meshing to spread?

Smith discusses local bottom-up sustainability initiatives as prototypes, which can, in offering convivial activity for community building and alliance formation, create new institutions $(2018, n p)$. The idea of prototype is useful here to remind that every combination of values, actions and tools to be found in place will be evolving differently, as will the resulting mesh. Whether or not we wish to give the resultant platforms of platforms the status of institution, the thickening of relations over time points towards the creation of more stable and established ways of doing local sharing. This makes the mesh, first, more visible and finally more invisible as, over time, it becomes possible to forget the evolution of different elements. ${ }^{9}$ One last role that networked tools could, therefore, embrace is helping to understand the process of meshing and the conditions enabling it. This could document institutionalization, supporting recognition of value before the processes of growing together are lost from sight. As a succession of local histories, repository of experiments and processor of complex data for different conditions, analysis of meshing would be a difficult but fascinating tool.

\section{Conclusion: Valuing finite resources}

Pargman et al. (2016) ask if the sharing economy can help provide guaranteed, fair and equal access to resources in a shrinking economy or manage tendencies to hoard and monopolize. These questions address long-term environmental crisis (IPCC 2018). Technology has its place in responding, but we need careful deployment. We do not want to impact adversely qualities needed to deal with these social stresses.

\footnotetext{
${ }^{9}$ It could be argued that elected local councils have gone this way - once the sharing economy of the nineteenth century.
} 
Environmental and social sustainability are tightly linked - we will sustain in place because of environmental action, while the social aspects of life around us make it more likely that we care about our world, act on it and find meaning in solidarity. Looming challenges make strengthening the fabric of society critical. Martin (2016) warns 'If the sharing economy follows [the] pathway of corporate co-option it appears unlikely to drive a transition to sustainability' (p. 149). The new wave of technologies claiming social and environmental good in the shape of the sharing economy may let us down.

In this paper, we have paid particular attention to the scale at which platforms perform, across cultures and locations, and how trust is situated, but we have also observed the tendency of the scaling sharing economy to financialize transactions and perform other 'crisp' interactions using software. Finding easy ways to use idle goods may produce side-effects that are less welcome than the more challenging task of attending to social fabric. Any act of renting, buying or paying a subscription may be a step to promoting resource sustainability, but the promotion of renting as sharing has different societal consequences. We began this paper by suggesting that sharing embedded in everyday caring practices contributes more than the resource management offered by services that trade idle capacity. The sustainability challenges for the most aggressive brokers in the sharing economy fall into four areas:

- The winner-takes-all model requires services to beat the competition, leading to invisibility for contrasting (collective) forms of sharing, to one-size-fits-all services, and to a culture of monolithic providers that are remote from the people using the services.

- Sharing is individualized. The digital platform does the trust work, replacing collective human learning.

- Promotion of financial rewards conflicts with existing desires to do something with/for others based on mutual care, not monetary gain. The meaning of sharing as belonging and caring becomes compromised.

- The monetization of peer-to-peer exchange reduces even more things to a price. Many things we need to protect (air, biodiversity, water) will not be valued if the only measure of value is financial.

These patterns are associated with unscrupulous scaling, if not scalability. But platforms can also be used to promote a different socio-economic structure. To contrast with this divisive approach, this paper has focused on local structures to support collaborative activity and develop social cohesion, giving examples of the spatial, temporal and social issues involved in caring-based sharing and discussing how meshing of platforms offers an alternative to these competitors in the global economy. We have introduced the idea of a 'platform of platforms' to address this, noting that, while there is growing literature on organizations that challenge current economic 
arrangements, there is less on neighbourhoods. To talk scale, this places our study between studies of individual platforms and those of the economies in which they operate. Specifically, we present the difference between meshing and scaling as a means to look at sharing and the sharing of shared infrastructures. This allows us to explore the economics of scaling and meshing orientations and the values they speak to. It also reveals the spatial work in how services are constructed.

We have drawn on material from two small areas of south London with much in common. The detail cannot be generalized, but the broader points - of what to support and how to recognize it as evolving and enmeshed - remain true across contexts. We have teased out the organizational structures and processes that help develop collective sharing over time. Indeed, our contribution has been to look at how individual initiatives interlace, from the bottom up, to become part of a greater phenomenon, while analyzing the spatial and temporal dimensions of how people, values, actions and tools come together in particular places.

Sharing practices can create layers of sociotechnical infrastructure as the connections between people become as important as the things they possess. We close by advocating design for growth of shared initiative-taking that transcends market models to respond to local interests and broader environmental realities. The suggestions here are brief and partial, given to encourage thought about neighbourhoods and their potential. They point to a need, rather than producing a solution. They attempt to refocus energy from dominant discussions of networks and platforms, by giving a how, and just as importantly, a why to thinking locally about network growth and economies of sharing.

\section{Acknowledgments}

With thanks to the EPSRC for funding the Design for Sharing project (part of grant no: EP/K003593/1), for the help of our interviewees and for the insights of our anonymous reviewers.

Open Access This article is distributed under the terms of the Creative Commons Attribution 4.0 International License (http://creativecommons.org/licenses/by/4.0/), which permits unrestricted use, distribution, and reproduction in any medium, provided you give appropriate credit to the original author(s) and the source, provide a link to the Creative Commons license, and indicate if changes were made.

\section{References}

Adur \& Worthing (2017). Adur \& Worthing Councils win award for pioneering digital app that helps GPs and their patients. Adur \& Worthing Councils, 14 July 2017. Available at: https://www.adurworthing.gov.uk/news/archive/pr17-095.html 
Aigrain, Philippe (2011). Sharing: Culture and the Economy in the Internet Age, Amsterdam: Amsterdam University Press

AirBnB (2014). New Study Reveals A Greener Way to Travel: Airbnb Community Shows Environmental Benefits of Home Sharing. Airbnb. Available at: https://www.airbnb.co.uk/press/ news/new-study-reveals-a-greener-way-to-travel-airbnb-community-shows-environmental-benefitsof-home-sharing.

Albinsson, Pia A.; and B. Yasanthi Perera (2012). AlternativeMarketplaces in the 21st Century: Building Community through Sharing Events. Journal of Consumer Behaviour, vol. 11, pp. 303315

Barkhuus, Louise; and Juliana Tashiro (2010). Student socialization in the age of Facebook, CSCW '10, Proceedings of the 2010 ACM International Conference on Computer-Supported Cooperative Work and Social Computing, Savannah, GA, USA, 06-10 February 2010. New York, NY: ACM, pp. 133-142

Bauwens, Michel (2012). Synthetic Overview of the Collaborative Economy, P2P Foundation. Available at: https://p2pfoundation.net/wp-content/uploads/2018/02/Synthetic-overview-of-the-collaborative-economy.pdf

Belk, Russell (2007). Why not share rather than own? The Annals of the American Academy of Political \& Social Science 2007, vol. 611, no. 1, pp. 126-140

Belk, Russell (2014). Sharing Versus Pseudo-Sharing in Web 2.0, Anthropologist, vol. 18, no. 1, pp. $7-23$

Belk, Russell (2017a). Sharing without Caring. Cambridge Journal of Regions, Economy and Society, vol. 10 , no. 2 , pp. 249-261

Belk, Russell (2017b). Sharing, Materialism, and Design for Sustainability, Routledge Handbook of Sustainable Product Design, edited by Jonathan Chapman, London: Routledge, pp. 160-172

Benkler, Yochai (2004). Sharing Nicely: On Shareable Goods and the Emergence of Sharing as a Modality of Economic Production, Yale Law Journal, vol. 114 (November), pp. 273-358.

Biørn-Hansen, Aksel; and Maria Håkansson (2018). Building Momentum: Scaling up Change in Community Organizations. CSCW'18, Proceedings of the 2018 ACM International Conference on Computer-Supported Cooperative Work and Social Computing, Jersey City, NJ, USA, 03-07 November 2018. New York, NY: ACM, pp. 410-422.

BIS (2014). Unlocking the sharing economy: independent review, UK Department for Business, Innovation and Skills. Available at: https:/www.gov.uk/government/publications/unlocking-thesharing-economy-independent-review

Botero, Andrea; Ann Light; Lone Malmborg; Sanna Marttila; Mariana Salgado; and Joanna SaadSulonen (2016). Becoming Smart Citizens. How Replicable Ideas Jump. Workshop at Design and the City Conference, Amsterdam, June 2016.

Botsman, Rachel (2017) Who Can You Trust?: How Technology Brought Us Together and Why It Might Drive Us Apart, New York, NY: Public Affairs

Botsman, Rachel; and Roo Rogers (2010). What's Mine is Yours: The Rise of Collaborative Consumption, New York: Harper Business

Bradley, Karin; and Daniel Pargman (2017). The Sharing Economy as the Commons of the 21 st century. Cambridge Journal of Regions, Economy and Society, vol. 10, no. 2, pp. 231-247

Carroll, John M.; and Victoria Bellotti (2015). Creating value together: The emerging design space of peer-To-peer currency and exchange. CSCW '15, Proceedings of the 2015 ACM International Conference on Computer-Supported Cooperative Work and Social Computing, Vancouver, BC, Canada, 14-18 March, 2015. New York, NY: ACM, pp. 1500-1510

Choudary, Sangeet P. (2015). Platform Scale: How an emerging business model helps startups build large empires with minimum investment, San Francisco: Platform Thinking Labs 
Coote, Anna; and Nina Goodwin (2010). The Great Transition: Social justice and the Core Economy, London: New Economics Foundation

Coppola, Frances (2016). Scaling the Sharing Economy. Forbes, 18 January 2016. Available at: https://www.forbes.com/sites/francescoppola/2016/01/18/scaling-the-sharing-economy/ $\# 1125 \mathrm{a} 2206926$

Cox, Michael; Gwen Arnold; and Sergio Villamayor Tomás (2010). A Review of Design Principles for Community-based Natural Resource Management. Ecology and Society, vol. 15, no. 4. Available at: https://www.ecologyandsociety.org/vol15/iss4/art38/main.html

Crompton, Tom (2010). Common Cause: The Case for Working with our Cultural Values, London: WWF-UK

Curtis, Steven K.; and Matthias Lehner (2019). Defining the Sharing Economy for Sustainability, Sustainability, vol. 11, no 3: 567, np. Available at: https://www.mdpi.com/2071-1050/11/3/567

Le Dantec, Christopher A.; and Carl DiSalvo (2013). Infrastructuring and the formation of publics in participatory design. Social Studies of Science, vol. 43, no. 2, pp. 241-264.

Davies, Anna R.; Betsy Donald; Mia Gray; and Janelle Knox-Hayes (2017). Sharing economies: Moving beyond binaries in a digital age. Cambridge Journal of Regions, Economy and Society, vol. 10 , no. 2 , pp. $209-230$

Dillahunt, Tawanna R.; and Amelia R. Malone. 2015. The Promise of the Sharing Economy among Disadvantaged Communities. CHI '15, Proceedings of the 33rd Annual ACM Conference on Human Factors in Computing Systems, Seoul, Republic of Korea, 18-23 April 2015. New York, NY: ACM, pp. 2285-2294.

Dillahunt, Tawanna R.; Xinyi Wang; Earnest Wheeler; Hao Fei Cheng; Brent Hecht; and Haiyi Zhu (2017). The Sharing Economy in Computing: A Systematic Literature Review. CSCW '17, Proceedings of the ACM: Human-Computer Interaction: Vol. 1: Issue CSCW: Computer-Supported Cooperative Work and Social Computing. New York, NY: ACM, pp. $1-26$

DiSalvo, Carl; and Tom Jenkins (2017). Fruit Are Heavy: A prototype Public IoT system to support Urban Foraging. DIS '17, Proceedings of the 2017 Conference on Designing Interactive Systems, Edinburgh, United Kingdom, 10-14 June, 2017. New York, NY: ACM, pp. 541-553.

Fischer, Joel E.; James A Colley; Ewa Luger; Michael Golembewski; Enrico Costanza; Sarvapali D Ramchurn; Stephen Viller; Ian Oakley; and Jon E. Froehlich (2016). New Horizons for the IoT in Everyday Life: Proactive, Shared, Sustainable. Workshop. Ubicomp'16, Adjunct Proceedings for ACM International Conference on Ubiquitous Computing, Heidelberg, Germany, 12-16 September 2016. New York, NY: ACM, pp. 657-660

Fisher, Eran (2010). Media and new Capitalism in the Digital Age: The Spirit of networks, New York: Palgrave Macmillan

Frenken, Koen; and Juliet Schor (2017). Putting the sharing economy into perspective, Environmental Innovation and Societal Transitions, 23, pp. 3-10

Gauntlett, David (2011). Making is Connecting: The Social Meaning of Creativity, from DIY and Knitting to YouTube and Web 2.0. Cambridge, UK: Polity Press.

Gawer, Annabelle (2009). Introduction. Platforms, Markets and Innovation: An Introduction. In Platforms, Markets and Innovation, edited by Annabelle Gawer, London: Edward Elgar, pp. 1-16.

Hakken, David; Maurizio Teli; and Barbara Andrews (2016). Beyond Capital: Values, Commons, Computing, and the Search for a Viable Future, Abingdon, UK: Routledge

Harburg, Emily; Julie Hui; Michael Greenberg; and Elizabeth M. Gerber (2015). Understanding the Effects of Crowdfunding on Entrepreneurial Self-Efficacy, CSCW '15, Proceedings of the 18th ACM Conference on Computer Supported Cooperative Work and Social Computing, Vancouver, BC, Canada, 14-18 March 2015. New York, NY: ACM, pp. 3-16

Hawlitschek, Florian; Timm Teubner; and Christof Weinhardt (2016), Trust in the Sharing Economy. Die Unternehmung - Swiss Journal of Business Research and Practice, vol. 70, pp. 26-44 
Heitlinger, Sara; Nick Bryan-Kinns; and Janis Jefferies (2014). The Talking Plants: An Interactive System for Grassroots Urban Food-Growing Communities, CHI '14, Proceedings of the 32nd Annual ACM Conference on Human Factors in Computing Systems, Toronto, Ontario, Canada, 26 April-01 May 2014. New York, NY: ACM, pp. 459-462

Heitlinger, Sara; Nick Bryan-Kinns; and Rob Comber (2018). Connected Seeds and Sensors: Codesigning Internet of0020Things for Sustainable Smart Cities with urban food-growing communities. PDC '18, Proceedings of the ACM Participatory Design Conference, Hasselt and Genk, Belgium, 20-24 August 2018. New York, NY: ACM, Article No. 18.

Hillgren, Per-Anders; Anna Seravalli; and Anders Emilson (2011). Prototyping and infrastructuring in design for social innovation. CoDesign, vol. 7, nos. 3-4, pp. 169-183.

Hui, Julie S.; and Elizabeth M. Gerber (2017). Developing Makerspaces as Sites of Entrepreneurship, CSCW '17, Proceedings of the 2017 ACM Conference on Computer Supported Cooperative Work and Social Computing, Portland, Oregon, USA, 25 February-01 March 2017. New York, NY: ACM, pp. 2033-2038

Ikkala, Tapio; and Airi Lampinen (2015). Monetizing Network Hospitality: Hospitality and Sociability in the Context of Airbnb. CSCW '15, Proceedings of the 18th ACM Conference on Computer Supported Cooperative Work \& Social Computing, Vancouver, BC, Canada, 14-18 March 2015. New York, NY: ACM, pp. 1033-1044.

Ingold, Tim (2011). Being Alive: Essays on movement, knowledge and description. Abingdon: Routledge

IPCC (2018). Summary for Policymakers. Global Warming of $1.5^{\circ} \mathrm{C}$. An IPCC Special Report on the impacts of global warming of $1.5^{\circ} \mathrm{C}$ above pre-industrial levels and related global greenhouse gas emission pathways, in the context of strengthening the global response to the threat of climate change, sustainable development, and efforts to eradicate poverty. Geneva: World Meteorological Organization. Available at: http//report.ipcc.ch/sr15/pdf/sr15_spm_final.pdf

IxD (2018). Available at: https://www.interaction-design.org/literature/article/contextual-interviewsand-how-to-handle-them

Jegou, François; and Ezio Manzini (2008), Collaborative services: Social Innovation and Design for Sustainability. Milano: Poli.design Edizioni.

Jung, Jiwon; and Kun-Pyo Lee (2017). Curiosity or Certainty?: A Qualitative, Comparative Analysis of Couchsurfing and Airbnb User Behaviors. CHI '17, Proceedings of the Conference Extended Abstracts on Human Factors in Computing Systems, Denver, Colorado, USA, 06-11 May 2017. New York, NY: ACM, pp. 1740-1747

Jung, Jiwon; Susik Yoon; Seunghyun Kim; SangKeun Park; Kun-Pyo Lee; and Uichin Lee (2016). Social or Financial Goals? Comparative Analysis of User Behaviors in Couchsurfing and Airbnb. CHI '16, Proceedings of the Conference on Human Factors in Computing Systems, San Jose, California, USA, 07-12 May 2016. New York, NY: ACM, pp. 2857-2863

Kalamar, Anthony (2013). Sharewashing is the New Greenwashing, OpEdnews, 13 May 2013. Available at: https://www.opednews.com/articles/2/Sharewashing-is-the-New-Gr-by-AnthonyKalamar-130513-834.html?p=2\&f=Sharewashing-is-the-New-Gr-by-Anthony-Kalamar-130513834.html.

Karasti, Helena (2014). Infrastructuring in participatory design. PDC '14, Proceedings of the 13th Participatory Design Conference: Research Papers-Vol. 1, Windhoek, Namibia, 06-10 October 2014. New York, NY: ACM, pp. 141-150.

Karasti, Helena; and Karen S Baker (2004). Infrastructuring for the long-term: Ecological information management. HICSS '04, 37th Hawaii International Conference on System Sciences, 5-8 January 2004, Big Island, HI, USA. New York: IEEE computer society, pp. 10-22.

Katrini, Eleni (2018), Sharing Culture: On Definitions, Values, and Emergence, The Sociological Review, vol. 66, no. 2, pp. 425-446 
Korn, Matthias; and Amy Voida (2015). Creating Friction: Infrastructuring Civic Engagement in Everyday Life. Critical Alternatives 2015: The fifth decennial Aarhus conference, Aarhus, Denmark, 17-21 August, 2015. Aarhus, Denmark: Aarhus University Press, pp. 145-156.

Lampinen, Airi (2016). Hosting Together via Couchsurfing: Privacy Management in the Context of Network Hospitality. International Journal of Communication, vol. 10, no 20, pp. 1581-1600

Lampinen, Airi; and Barry Brown (2017). Market Design for HCI: Successes and Failures of Peer-to-Peer Exchange Platforms. CHI'17, Proceedings of the annual conference on Human factors in computing systems, Denver, Colorado, USA, 06-11 May 2017. New York, NY: ACM, pp. 4331-4343

Lampinen, Airi; and Coye Cheshire (2016). Hosting via Airbnb: Motivations and Financial Assurances in Monetized Network Hospitality. CHI'16, Proceedings of the annual conference on Human factors in computing systems, San Jose, California, USA, 07-12 May 2016. New York, NY: ACM, pp. 1669-1680

Lampinen, Airi; Kai Huotari; and Coye Cheshire (2015a). Challenges to Participation in the Sharing Economy: The Case of Local Online Peer-to-Peer Exchange in a Single Parents' Network. Interaction Design and Architecture(s) Journal - IxD\&A, no. 24, pp. 16-32

Lampinen, Airi; Victoria Bellotti; Coye Cheshire; and Mary L. Gray (2015b). CSCW and the Sharing Economy: The Future of Platforms as Sites of Work Collaboration and Trust, CSCW '15, Proceedings of the 18th ACM Conference on Computer Supported Cooperative Work and Social Computing Companion, Vancouver, BC, Canada, 14-18 March 2015. New York, NY: ACM, pp. 491-497

Light, Ann (forthcoming). Designing the Economics of the Sharing Economy: Towards Sustainable Management, Handbook of the Sharing Economy, edited by Russell Belk, Giana Eckhardt and Fleura Bardhi, London: Edward Elgar.

Light, Ann; and Jo Briggs (2017). Crowdfunding Platforms and the Design of Paying Publics, CHI '17, Proceedings of the annual conference on Human factors in computing systems, Denver, Colorado, USA, 06-11 May 2017. New York, NY. ACM, pp. 797-809

Light, Ann; and Clodagh Miskelly (2008). Brokering between Heads and Hearts: an analysis of designing for social change. Proceedings of Design Research Society Conference, Sheffield, June 2008.

Light, Ann; and Clodagh Miskelly (2014). Design for Sharing. Newcastle: Northumbria University Working Paper. Available at: https://designforsharingdotcom.files.wordpress.com/2014/09/designfor-sharing-webversion.pdf

Light, Ann; and Clodagh Miskelly (2015). Sharing Economy vs Sharing Cultures? Designing for social, economic and environmental good, Interaction Design and Architecture(s) Journal $I x D \& A$, no. 24 , pp. $49-62$

Luckner, Naemi; Geraldine Fitzpatrick; Katharina Werner; and Özge Subasi (2015). Setting up and Running a Sharing Service: an Organisational Perspective. Interaction Design and Architecture(s) Journal - IxD\&A, no. 24, pp. 63-80.

Makwana, Rajesh (2013). Values and the sharing economy, Shareable.net blog, 28 February 2013: Available at: http://www.shareable.net/blog/values-and-the-sharing-economy

Martin, Chris J. (2016), The sharing economy: A pathway to sustainability or a nightmarish form of neoliberal capitalism?, Ecological Economics, vol. 121, pp. 149-159

Martin, Chris J.; Paul Upham; and Leslie Budd (2015). Commercial orientation in grassroots social innovation: Insights from the sharing economy, Ecological Economics, vol. 120, pp. 240-251.

Massey, Doreen (2005). For Space. London: Sage.

McCann, Duncan (2018). Disrupting Together: The Challenges (And Opportunities) For Platform CoOperatives, 18 July 2018, New Economics Foundation Blog: Available at: https:// neweconomics.org/2018/07/disrupting-together

Messeter, Jorn; Eric Gronvall; Lone Malmborg; Geraldine Fitzpatrick; Özge Subasi; Eva Brandt; Martin Sønderlev Christensen; and Thomas Raben (2016). Migration Of A Sharing Platform From 
Copenhagen To Aarhus: A Live Exploration Of How Social Innovations May Travel. PDC '16, Proceedings of the 14th Participatory Design Conference Short Papers, Interactive Exhibitions, Workshops: Vol. 2, Aarhus, Denmark, 15-19 August 2016. New York, NY: ACM, pp. 107-108

Miller, Ethan (2009). Solidarity Economy: Key Concepts and Issues, Solidarity Economy I: Building Alternatives for People and Planet, Papers and Reports from the 2009 U.S. Forum on the Solidarity Economy, edited by Emily Kawano, Thomas Neal Masterson and Jonathan TellerElsberg, Amherst, MA: Center for Popular Economics

Moazed, Alex; and Nicholas L. Johnson (2016). Modern Monopolies: What It Takes to Dominate the 21st Century Economy, New York: St. Martin's Press

Nardi, Bonnie (2019). Design in the Age of Climate Change. She Ji: The Journal of Design, Economics, and Innovation, vol. 5, no. 1, pp. 5-14

Offer, Shira (2012). The burden of reciprocity: Processes of exclusion and withdrawal from personal networks among low-income families. Current Sociology, vol. 60, pp. 788-805

O'Hara, Kenton P.; Michael Massimi; Richard Harper; Simon Rubens; and Jessica Morris (2014). Everyday dwelling with WhatsApp, CSCW '14, Proceedings of the 17th ACM conference on Computer Supported Cooperative Work and Social Computing, Baltimore, MD, USA, 15-19 February 2014. New York, NY: ACM, pp. 1-13

Okada, Shuhei (2014). Transformation of spaces and places in inner cities: The case of gentrification in Brixton since the riot in 1981. MPhil, London: Royal Holloway, University of London. Available at: https://core.ac.uk/download/pdf/28906664.pdf

Orsi, Janelle (2009). Four degrees of sharing. Shareable, 16 Sept 2009: Available at: http:// www.shareable.net/blog/four-degrees-of-sharing

Ostrom, Elinor (1990). Governing the Commons: The Evolution of Institutions for Collective Action, Cambridge: Cambridge University Press.

Ostrom, Elinor (1996). Crossing the Great Divide: Coproduction, Synergy, and Development, World Development, vol. 24, no. 6, pp. 1073-1087.

P2P Foundation (n.d.) 1.3 What does a P2P Economy look like?, Available at: https:// primer.commonstransition.org/1-short-articles/1-3-what-does-a-p2p-economy-look-like

Pansera, Mario; and Francesco Rizzi (2018). Furbish or perish: Italian social cooperatives at a crossroads, Organization, https://doi.org/10.1177/1350508418760980

Pargman, Daniel; Elina Eriksson; and Adrian Friday, (2016). Limits to the sharing economy. Limits '16, Proceedings of the Workshop on Computing Within Limits, Irvine, California, 08-10 June 2016. New York, NY, pp. 2:1-12:7

Pipek, Volkmar; and Volker Wulf (2009). Infrastructuring: Toward an integrated perspective on the design and use of information technology. Journal of the Association for Information Systems vol. 10, no. 5, pp. 447

Potter, Jonathan; and Margaret Wetherell (1987). Discourse and social psychology: beyond attitudes and behaviour. London: Sage.

Powley, Tanya (2018). Transport for London on course for £1bn deficit, Financial Times, 26 February 2018

Randers, Jorgen; Johan RockstrÖm; Per Espen Stoknes; Ulrich Golüke; David Collste; and Sarah Cornell (2018). Transformation is feasible: How to achieve the Sustainable Development Goals within Planetary Boundaries. A report to the Club of Rome, for its 50 years anniversary. 17 October 2018 from Stockholm Resilience Centre and BI Norwegian Business School, Club of Rome.

Raworth, Kate (2017). Doughnut Economics: Seven Ways to Think Like a 21st-Century Economist, White River Junction, VT: Chelsea Green Publishing Company.

Reillier, Laure C.; and Benoit Reillier (2017). Platform Strategy: How to Unlock the Power of Communities and Networks to Grow Your Business, New York: Routledge 
Robertson, Toni; and Ina Wagner (2015). CSCW and the Internet of Things, ECSCW '15: Proceedings of the 14th European Conference on Computer Supported Cooperative Work, San Francisco, California, USA, 26 February-02 March 2016. New York, NY: ACM, pp. 285-294

Scholz, Trebor (2014). Platform Cooperativism vs the Sharing Economy, Medium. Available at: https://medium.com/@ trebors/platform-cooperativism-vs-the-sharing-economy-2ea737flb5ad

Sennett, Richard (2012). Together: The Rituals, Pleasures and Politics of Co-Operation. London: Allen Lane.

Seravalli, Anna (2018) Infrastructuring Urban Commons over Time: Learnings from Two Cases, PDC '18, Proceedings of the Participatory Design Conference, Hasselt and Genk, Belgium, 20-24 August 2018. New York, NY: ACM, pp. 53-56

Shareable (eds) (2018). Sharing Cities: Activating the Urban Commons. Shareable. Available at: https://www.shareable.net/sites/default/files/SharingCities-ActivatingtheUrbanCommons.pdf

Slee, Tom (2015). What's Yours Is Mine: Against the Sharing Economy. New York and London: Or Books

Smith, Adrian (2018). Forking the SDGs: How prototypes could transform the new global goals. STEPS Blog, 4 March 2018. Available at: https://steps-centre.org/blog/forking-sdgs-prototypestransform-new-global-goals/

Smith, Adrian; and Ann Light (2017). Cultivating sustainable developments with makerspaces. Liinc em revista, vol. 13, no. 1, pp. 162-174.

Star, Susan L. (1999). The ethnography of infrastructure. American Behavioral Scientist, vol. 43, no. 3, pp. 377-391.

Star, Susan L.; and Karen Ruhleder (1994). Steps towards an ecology of infrastructure: complex problems in design and access for large-scale collaborative systems. CSCW '94, Proceedings of the 1994 ACM Conference on Computer Supported Cooperative work, Chapel Hill, North Carolina, USA, 22-26 October 1994. New York, NY: ACM, pp. 253-264.

Steed, Susan (2013). Money and Giving: Do Financial Incentives deter or encourage Co-operative behaviour?. London: New Economics Foundation. Available at: http://www.neweconomics.org/ publications/entry/money-and-giving

Stokes, Kathleen; Emma Clarence; Lauren Anderson; and April Rinne (2014). Making Sense of the Collaborative Economy, London: NESTA and Collaborative Lab, Sept 2014

Stone, Brad; and Olivia Zaleski (2017). Airbnb Enters the Land of Profitability, 26 January 2017, Bloomberg. Available at: https://www.bloomberg.com/news/articles/2017-01-26/airbnb-enters-theland-of-profitability

Toombs, Austin (2015). Enacting Care Through Collaboration in Communities of Makers, CSCW '15, Proceedings of the 18th ACM Conference Companion on Computer Supported Cooperative Work \& Social Computing, Vancouver, BC, Canada, 14-18 March 2015. New York, NY: ACM, pp. 81-84

Vlachokyriakos, Vasilis; Clara Crivellaro; Peter Wright; and Patrick Olivier (2018). Infrastructuring the Solidarity Economy: Unpacking Strategies and Tactics in Designing Social Innovation. CHI '18, Proceedings of the 2018 CHI conference on human factors in computing systems, Montreal QC, Canada, 21-26 April 2018. New York, NY: ACM, pp. 481-493

Vyas, Dhaval; and Tawanna Dillahunt (2017). Everyday Resilience: Supporting Resilient Strategies among Low-socioeconomic-status Communities. CSCW '17, Proceedings of the ACM: HumanComputer Interaction: Vol. 1: Issue CSCW: Computer-Supported Cooperative Work and Social Computing. New York, NY: ACM, pp. 105:1-105:21

Warneken, Felix; and Michael Tomasello (2008). Extrinsic Rewards Undermine Altruistic Tendencies in 20-Month-Olds, Developmental Psychology, vol. 44, no. 6, pp. 1785-1788

Weber, Cheyenna Layne (2011). Sharing power: Building a solidarity economy, Shareable, 5 October 2011. Available at: https://www.shareable.net/blog/sharing-power-building-a-solidarity-economy,

White, Richard J. (2009). Explaining why the non-commodified sphere of mutual aid is so pervasive in the advanced economies: Some case study evidence from an English city, Int. J. Sociology and Social Policy, vol. 29, nos. 9/10, pp. 457-472 
Williams, Aime (2016). How Airbnb lost its soul. Financial Times, 15 April 2016. Available at: https:/www.ft.com/content/1fbef27e-022b-11e6-ac98-3c15a1aa2e62

Yu, Howard (2018). For Some Platforms, Network Effects Are No Match for Local Know-How. Harvard Business Review, 26 July 2018. Available at: https://hbr.org/2018/07/for-some-platformsnetwork-effects-are-no-match-for-local-know-how

Publisher's Note Springer Nature remains neutral with regard to jurisdictional claims in published maps and institutional affiliations. 